\title{
Studi Kehilangan Air Komersial (Studi Kasus: PDAM Kota Kendari Cabang Pohara)
}

\author{
Iis Puspitasari dan Alfan Purnomo \\ Departemen Teknik Lingkungan, Fakultas Teknik Sipil dan Perencanaan, Institut Teknologi Sepuluh Nopember (ITS) \\ e-mail: alfanpurnomo@gmail.com
}

\begin{abstract}
Abstrak-Kehilangan air merupakan salah satu masalah yang sering dialami oleh PDAM di Indonesia. Menurut data resmi PDAM Kota Kendari tahun 2015, rata-rata kehilangan air PDAM Kota Kendari Cabang Pohara mencapai 57,99\% yaitu sebesar 3.041.257 $\mathrm{m}^{3}$. Tujuan penelitian ini yaitu mengidentifikasi komponen kehilangan air komersial dan menetapkan strategi penurunan kehilangan air komersial pada PDAM Kota Kendari Cabang Pohara. Penelitian ini menggunakan metode neraca air yang didapatkan dari data primer dan sekunder yaitu konsumsi resmi dan kehilangan air. Analisis perhitungan neraca air digunakan agar dapat mengetahui komponen kehilangan air komersial pada PDAM secara lebih spesifik. Tingkat kehilangan air yang diperoleh dari hasil perhitungan neraca air yaitu kehilangan air fisik sebesar $54,23 \%$ dan kehilangan air komersial sebesar $3,76 \%$. Kehilangan air komersial ini setara dengan $197.302 \mathrm{~m}^{3}$ per tahun dengan kerugian sebesar Rp 2.261.825.700,- per tahun.
\end{abstract}

Kata Kunci-kehilangan air, komersial, PDAM Kota Kendari.

\section{PENDAHULUAN}

$\mathrm{K}$ EHILANGAN air merupakan salah satu masalah yang sering dialami oleh PDAM di Indonesia. Menurut data resmi PDAM Kota Kendari tahun 2015 rata-rata kehilangan air PDAM Kota Kendari Cabang Pohara mencapai sekitar $57,99 \%$ yaitu sebesar $3.041 .257 \mathrm{~m}^{3}$. Tingkat kehilangan air yang tinggi sangat mempengaruhi kemampuan suplai air bersih PDAM terhadap konsumen. Semakin besar tingkat kehilangan air yang terjadi maka kemampuan suplai air bersih PDAM semakin menurun, karena PDAM akan terus merugi dari tahun ke tahun [1]. Kehilangan air terdiri dari kehilangan yang disebabkan oleh fisik (teknis) dan kehilangan yang disebabkan oleh non fisik (komersial). Penyebab utama kehilangan air oleh fisik disebabkan oleh kebocoran pipa dan limpahan tangki reservoir. Sedangkan kehilangan air non fisik disebabkan beberapa faktor diantaranya konsumsi tak resmi, ketidakakuratan meter pelanggan, dan kesalahan penanganan data [2].

Tindakan yang diperlukan untuk mengurangi tingkat kehilangan air ialah mengidentifikasi seberapa besar dan dimana kehilangan air terjadi serta kerugian finansial akibat kehilangan air tersebut. Besarnya nilai finansial kerugian akibat kehilangan air komersial merupakan alasan yang kuat mengapa harus dilakukan berbagai upaya untuk menurunkan tingkat kehilangan air komersial pada PDAM. Analisis terhadap unsur-unsur penyebab kehilangan air komersial perlu dilakukan guna melakukan pendekatan langkah-langkah pengendalian kehilangan air yang sesuai. Pengendalian kehilangan air yang sesuai dengan masalah yang dihadapi sangat diperlukan guna mencapai hasil yang maksimal.

\section{METODOLOGI}

Metode yang digunakan dalam penelitian ini adalah survei. Survei ini meliputi tahap pengumpulan data dan tahap analisis data.

\section{A. Tahap Pengumpulan Data}

Berdasarkan jenis data yang dibutuhkan, maka tahap pengumpulan data dibagi menjadi 2 , yaitu:

1. Data Sekunder

Data sekunder adalah data yang diperoleh dari PDAM

Kota Kendari, berupa:

- Gambaran umum wilayah penelitian.

- Peta pelayanan PDAM Kota Kendari Cabang Pohara.

- Volume input air.

- Jumlah air terjual.

- Jumlah pelanggan.

- Tarif harga air.

2. Data Primer

Data primer adalah data yang diperoleh dari observasi (hasil pengamatan dan pengukuran langsung di lapangan) serta wawancara dengan PDAM Kota Kendari Cabang Pohara. Data primer berupa:

- Data keakuratan meter pelanggan.

\section{B. Tahap Analisis Data}

Dalam tahap ini dilakukan pengelompokan data berdasarkan komponen atau sumbernya yaitu:

- Konsumsi resmi berekening terdiri dari konsumsi bermeter berekening dan konsumsi tak bermeter berekening.

- Konsumsi resmi tak berekening terdiri dari konsumsi bermeter tak berekening dan konsumsi tak bermeter tak berkening.

- Keakuratan meter pelanggan.

- Tipe meteran dan umur meter air.

- Perhitungan volume suplai air.

- Perhitungan kehilangan air komersial.

- Perhitungan tarif rata-rata 1 tahun.

- Perhitungan biaya akibat kehilangan air.

\section{HASIL DAN PEMBAHASAN}

\section{A. Data Eksisting atau Data Sekunder}

Jumlah penduduk yang terlayani oleh PDAM Kota Kendari pada tahun 2014 sebanyak 115.171 jiwa atau sebesar 35,7\%. Sistem penyaluran air pada PDAM Kota Kendari Cabang Pohara terdapat sistem in dan sistem out. Sistem in ialah 
penyaluran air dari IPAM yang dipompa kemudian masuk ke sistem distribusi Cabang Pohara. Sedangkan sistem out ialah penyaluran air menuju cabang Anggoya dan Anduonohu melalui Booster Wua-Wua dan Booster Kendari Beach.

\section{Volume Input Air}

Volume air ialah debit produksi air yang diproduksi oleh PDAM Kota Kendari Cabang Pohara dikurangi dengan konsumsi berekening yang ditunjukkan pada Tabel 1. Total volume input air pada tahun 2015 yaitu $7.122 .437 \mathrm{~m}^{3} /$ tahun dengan rata-rata per bulan yaitu $593.536 \mathrm{~m}^{3} / \mathrm{bulan}$.

Tabel 1.

Volume Input Air PDAM Kota Kendari Cabang Pohara Tahun 2015

\begin{tabular}{ccc}
\hline \hline Bulan ke- & $\begin{array}{c}\text { Volume Input Air } \\
\left(\mathrm{m}^{3} / \text { bulan }\right)\end{array}$ & $($ L/detik $)$ \\
\hline 1 & 614.549 & 237,09 \\
2 & 605.170 & 233,48 \\
3 & 618.548 & 238,64 \\
4 & 641.793 & 247,61 \\
5 & 680.936 & 262,71 \\
6 & 607.755 & 234,47 \\
7 & 583.686 & 225,19 \\
8 & 536.187 & 206,86 \\
9 & 590.176 & 227,69 \\
10 & 511.282 & 197,25 \\
11 & 522.155 & 201,45 \\
12 & 610.200 & 235,42 \\
Total 1 tahun & 7.122 .437 & $2.747,85$ \\
Rata-rata per bulan & 593.536 & 228,99 \\
\hline \hline
\end{tabular}

Tabel 2.

Total Konsumsi Resmi Berekening PDAM Kota Kendari Cabang Pohara Tahun 2015

\begin{tabular}{ccccc}
\hline \hline $\begin{array}{c}\text { Bulan } \\
\text { ke- }\end{array}$ & \multicolumn{2}{c}{$\begin{array}{c}\text { Air }\left(\mathrm{m}^{3}\right) \\
\text { Molualan }\end{array}$} & \multicolumn{2}{c}{ Pendapatan $(\mathrm{Rp})$} \\
& SR & $\begin{array}{c}\text { Mobil } \\
\text { Tangki }\end{array}$ & SR & $\begin{array}{c}\text { Mobil } \\
\text { Tangki }\end{array}$ \\
\hline 1 & 185.824 & 1.201 & 2.064 .906 .000 & 32.155 .000 \\
2 & 200.694 & 733 & 2.191 .676 .000 & 17.875 .000 \\
3 & 185.088 & 928 & 2.042 .724 .000 & 29.000 .000 \\
4 & 193.847 & 1.180 & 2.174 .440 .000 & 35.440 .000 \\
5 & 187.160 & 933 & 2.169 .707 .000 & 25.800 .000 \\
6 & 201.798 & 749 & 2.263 .917 .000 & 19.590 .000 \\
7 & 146.685 & 787 & 1.933 .221 .000 & 19.445 .000 \\
8 & 186.418 & 854 & 2.110 .984 .000 & 22.660 .000 \\
9 & 174.450 & 1.221 & 1.966 .084 .000 & 29.970 .000 \\
10 & 173.286 & 2.043 & 1.939 .058 .000 & 50.405 .000 \\
11 & 169.920 & 4.404 & 1.930 .146 .000 & 72.090 .000 \\
12 & 180.042 & 2.639 & 2.034 .776 .000 & 77.355 .000 \\
Total & 2.185 .212 & 17.672 & 24.821 .639 .000 & 431.785 .000 \\
Rata-rata & 182.101 & 1.473 & 2.068 .469 .917 & 35.982 .083 \\
\hline \hline
\end{tabular}

\section{Konsumsi Resmi Berekening}

Konsumsi resmi berekening ialah konsumsi resmi air atau volume pemakaian air oleh pelanggan yang dapat direkeningkan. Konsumsi resmi berekening terdiri atas konsumsi bermeter berekening yang bersumber dari pelanggan rumah tangga dan konsumsi tak bermeter berekening yang bersumber dari penjualan mobil tangki yang ditunjukkan Tabel 2. Konsumsi resmi berekening merupakan volume air yang terjual ditambah biaya dana meter dan administrasi. Total volume penjualan air untuk sambungan rumah tangga sebesar 2.185.212 $\mathrm{m}^{3} /$ tahun dan untuk mobil tangki sebesar 17.672 $\mathrm{m}^{3} /$ tahun.

- Konsumsi Resmi Tak Berekening

Konsumsi resmi tak berekening dibagi menjadi dua, yaitu konsumsi bermeter tak berekening dan konsumsi tak bermeter tak berekening. Konsumsi bermeter tak berekening merupakan banyaknya konsumsi air pada instansi-instansi yang dibebaskan dari pembayaran. Sedangkan konsumsi tak bermeter tak berekening merupakan banyaknya pemakaian air yang didistribusikan melalui tangki air PDAM untuk keperluan umum. Komponen data neraca air ini tidak tersedia pada PDAM Kota Kendari karena semua penggunaan air di PDAM Kota Kendari Cabang Pohara tidak ada yang dibebaskan pembayarannya.

- Tarif Harga Air

Tarif rata-rata didapatkan dari pembagian pendapatan selama satu tahun dengan pemakaian atau penjualan air selama satu tahun ditunjukkan pada Tabel 3 [3].

Tabel 3.

Rekapitulasi Total Jumlah Air Terjual dan Total Pendapatan

\begin{tabular}{ccc}
\hline \hline Bulan ke- & $\begin{array}{c}\text { Total Jumlah Air } \\
\text { Terjual }\left(\mathrm{m}^{3}\right)\end{array}$ & $\begin{array}{c}\text { Total } \\
\text { Pendapatan } \\
(\mathrm{Rp})\end{array}$ \\
\hline 1 & 187.025 & 2.097 .061 .000 \\
2 & 201.427 & 2.209 .551 .000 \\
3 & 186.016 & 2.071 .724 .000 \\
4 & 195.027 & 2.209 .880 .000 \\
5 & 188.093 & 2.195 .507 .000 \\
6 & 202.547 & 2.283 .507 .000 \\
7 & 147.472 & 1.952 .666 .000 \\
8 & 187.272 & 2.133 .644 .000 \\
9 & 175.671 & 1.996 .054 .000 \\
10 & 175.329 & 1.989 .463 .000 \\
11 & 174.324 & 2.002 .236 .000 \\
12 & 182.681 & 2.112 .131 .000 \\
Total dalam 1 & 2.202 .884 & 25.253 .424 .000 \\
tahun & \multicolumn{2}{c}{ Rp 11.464,- } \\
Tarif Rata-Rata & \multicolumn{2}{c}{} \\
\hline \hline
\end{tabular}

- Uji Akurasi Meter Air

Sampel dari 5 wilayah yang telah dipilih sebanyak 125 sampel diolah dan dihitung besar penyimpangannya dibandingkan dengan meter reference. Perhitungan menggunakan rumus berikut.

Penyimpangan $(\mathrm{P}): \sum(\mathrm{Mr}-\mathrm{Mc})$

Dimana:

P : Penyimpangan 
$\mathrm{Mr} \quad$ :(Metre Reference) Angka yang ditunjukkan oleh meter air sebagai reference (angka dari air yang mengalir)

Mc :(Metre Customer) Angka yang ditunjukkan oleh meter air pelanggan (angka di meter air pelanggan)

Sulitnya menyesuaikan jam pengaliran dan waktu sampling di lapangan sehingga hasil yang didapatkan dalam uji akurasi meter air ini sebanyak 80 sampel. Hasil kategori penyimpangan pembacaan meter air pelanggan (Mc) terhadap meter air angka (Mr) disajikan pada Tabel 4.

Tabel 4.

Hasil Penyimpangan Pembacaan Meter Air Pelanggan (Mc) Terhadap Meter Air Angka (Mr)

\begin{tabular}{ccc}
\hline \hline \multirow{2}{*}{ No } & $\begin{array}{c}\text { Hasil } \\
\text { Penyimpangan }\end{array}$ & $\begin{array}{c}\text { Jumlah Meter } \\
\text { Air }\end{array}$ \\
\hline 1 & Sangat Akurat $(0 \%)$ & 29 \\
2 & Akurat $(\leq 5 \%)$ & 8 \\
3 & Tidak Akurat $(\geq 5 \%)$ & 43 \\
& Total Sampel & 80 \\
\hline \hline
\end{tabular}

Terdapat dua jenis penyimpangan yaitu penyimpangan negatif dan penyimpangan positif. Penyimpangan negatif terjadi ketika Mc > Mr yang bermakna bahwa air yang dicatat oleh meter air pelanggan lebih banyak jumlahnya dari air yang benar-benar mengalir sehingga menguntungkan pihak PDAM. Sebaliknya penyimpangan positif terjadi ketika Mc < Mr yang bermakna bahwa air yang dicatat oleh meter air pelanggan lebih sedikit jumlahnya dari air yang benar-benar mengalir sehingga merugikan pihak PDAM. Hasil penyimpangan meter air pelanggan terhadap pengukuran debit pada Tabel 5 .

Tabel 5.

Hasil Penyimpangan Meter Air Pelanggan Terhadap Pengukuran Debit

\begin{tabular}{ccc}
\hline \hline No & Hasil Penyimpangan & $\begin{array}{c}\text { Jumlah Meter } \\
\text { Air }\end{array}$ \\
\hline 1 & Penyimpangan positif & 34 \\
2 & Penyimpangan & 17 \\
3 & negatif & 29 \\
\hline \hline
\end{tabular}

Proses pengambilan sampel sebanyak 80 sampel di 5 wilayah ini tidak ditemukan adanya sambungan liar yang biasa ditandai dengan perusakan segel meter air pelanggan. Namun sambungan liar pada proses pengambilan sampel tidak ditemukan.

- Kehilangan Air

Tingkat kehilangan air dihitung persentasenya berdasarkan selisih antara jumlah air yang didistribusikan $\left(\mathrm{m}^{3}\right)$ dengan jumlah air yang tercatat dalam rekening sehingga air tidak terbayarkan atau tidak terkonversi sebagai rupiah. Rumus untuk menghitung kehilangan air sebagai berikut [4].

Kehilangan air $=\sum$ air distribusi $-\sum$ air terjual (dalam $\mathrm{m}^{3} /$ waktu - bulan atau tahun)

Dimana:

Air terjual : air yang dibayar oleh pelanggan pada bulan atau kumulatif dalam satu tahun $\left(\mathrm{m}^{3}\right)$
Tingkat kehilangan air $(\%)=\frac{\text { kehilangan air }}{\text { air distribusi }} x 100 \%$

Kehilangan air PDAM Kota Kendari Cabang Pohara pada tahun 2015 disajikan pada Tabel 6.

Tabel 6.

Kehilangan Air PDAM Kota Kendari Cabang Pohara Tahun 2015

\begin{tabular}{|c|c|c|c|c|}
\hline $\begin{array}{c}\text { Bulan } \\
\text { ke- }\end{array}$ & $\begin{array}{c}\text { Air } \\
\text { Terdistribusi } \\
\left(\mathrm{m}^{3} / \text { bulan }\right)\end{array}$ & $\begin{array}{l}\text { Air Terjual } \\
\left(\mathrm{m}^{3} / \text { bulan }\right)\end{array}$ & $\begin{array}{r}\text { Kehilan } \\
\left(\mathrm{m}^{3} / \text { bulan }\right. \\
)\end{array}$ & $\begin{array}{l}\text { Air } \\
\%\end{array}$ \\
\hline 1 & 465.297 & 187.025 & 278.272 & $\begin{array}{c}59,81 \\
\%\end{array}$ \\
\hline 2 & 445.818 & 201.427 & 244.391 & $\begin{array}{c}54,82 \\
\%\end{array}$ \\
\hline 3 & 459.660 & 186.016 & 273.644 & $\begin{array}{c}59,53 \\
\%\end{array}$ \\
\hline 4 & 515.729 & 195.027 & 320.702 & $\begin{array}{c}62,18 \\
\%\end{array}$ \\
\hline 5 & 428.938 & 188.093 & 240.845 & $\begin{array}{c}56,15 \\
\%\end{array}$ \\
\hline 6 & 445.125 & 202.547 & 242.578 & $\begin{array}{c}54,50 \\
\%\end{array}$ \\
\hline 7 & 429.791 & 147.472 & 282.319 & $\begin{array}{c}65,69 \\
\%\end{array}$ \\
\hline 8 & 388.781 & 187.272 & 201.509 & $\begin{array}{c}51,83 \\
\%\end{array}$ \\
\hline 9 & 412.684 & 175.671 & 237.013 & $\begin{array}{c}57,43 \\
\%\end{array}$ \\
\hline 10 & 374.095 & 175.329 & 198.766 & $\begin{array}{c}53,13 \\
\%\end{array}$ \\
\hline 11 & 407.631 & 174.324 & 233.307 & $\begin{array}{c}57,23 \\
\%\end{array}$ \\
\hline 12 & 470.592 & 182.681 & 287.911 & $\begin{array}{c}61,18 \\
\%\end{array}$ \\
\hline Total & 5.244 .141 & 2.202 .884 & 3.041 .257 & \\
\hline Rata-rata & 437.012 & 183.574 & 253.438 & $\begin{array}{c}57,99 \\
\%\end{array}$ \\
\hline
\end{tabular}

- Kehilangan Air Komersial

Kehilangan air komersial meliputi dua komponen, yaitu konsumsi tak resmi dan ketidakakuratan meter pelanggan. Kehilangan air akibat akurasi meter pelanggan dapat diketahui dari hasil pengambilan sampel. Besar penyimpangan yang terjadi pada meter air akan dibagi dengan banyak sampel lalu dikalikan $100 \%$.

Kehilangan Air Komersial (KAK) $(\%)=\frac{\text { Penyimpangan }}{n} x 100 \%$

Berdasarkan teori bahwa penyimpangan positif saja yang dianggap komersial, namun penyimpangan negatif juga dimasukkan dalam perhitungan kehilangan air akibat akurasi meter karena volume air yang tercatat lebih banyak pada pelanggan dapat menutupi kerugian PDAM akibat penyimpangan positif sehingga didapatkan nilai kehilangan air komersial dari kehilangan air total pada Tabel 7.

Diketahui: $\quad$ PPenyimpangan positif $(+)=16,80 \mathrm{~L}$

$\Sigma$ Penyimpangan negatif $(-)=11,61 \mathrm{~L}$

$\overline{\Sigma \text { Penyimpangan }}=5,19 \mathrm{~L}$

Tabel 7.

Tingkat Kehilangan Air Komersial dari Kehilangan Air Total Akibat Pembacaan Meter Pelanggan

\begin{tabular}{ccc}
\hline \hline $\begin{array}{c}\text { SPenyimpanga } \\
\mathrm{n}\end{array}$ & Sampel & Tingkat \\
$(\mathrm{L})$ & Kehilangan \\
& (unit meter & Air Komersial (\%) \\
\hline
\end{tabular}




\begin{tabular}{lll}
\multicolumn{3}{c}{ air) } \\
\hline 5,19 & 80 & $6,49 \%$ \\
\hline \hline
\end{tabular}

Diketahui tingkat kehilangan air komersial dari kehilangan air total akibat pembacaan meter pelanggan adalah sebesar $6,49 \%$ sehingga untuk mengetahui besar kehilangan air komersial total dalam satuan volume/waktu tingkat kehilangan ini akan dikalikan dengan kehilangan air pada Tabel 7 menggunakan rumus berikut. Data besar kehilangan air komersial dari kehilangan air total akibat pembacaan meter pelanggan secara rinci disajikan pada Tabel 8 .

Kehilangan air komersial $=\% \mathrm{KAK} \times \mathrm{x}$ Kehilangan Air $\left(\mathrm{m}^{3} /\right.$ waktu-bulan atau tahun)

Tabel 8.

Kehilangan Air Komersial dari Kehilangan Air Total Akibat Pembacaan Meter Pelanggan

\begin{tabular}{|c|c|c|}
\hline Bulan ke- & $\begin{array}{c}\text { Kehilangan } \\
\qquad \begin{array}{c}\text { Air } \\
\left(\mathrm{m}^{3}\right)\end{array}\end{array}$ & $\begin{array}{c}\text { Besar Kehilangan } \\
\text { Air Komersial x 6,49\% } \\
\qquad\left(\mathrm{m}^{3}\right)\end{array}$ \\
\hline 1 & 278.272 & 18.053 \\
\hline 2 & 244.391 & 15.855 \\
\hline 3 & 273.644 & 17.753 \\
\hline 4 & 320.702 & 20.806 \\
\hline 5 & 240.845 & 15.625 \\
\hline 6 & 242.578 & 15.737 \\
\hline 7 & 282.319 & 18.315 \\
\hline 8 & 201.509 & 13.073 \\
\hline 9 & 237.013 & 15.376 \\
\hline 10 & 198.766 & 12.895 \\
\hline 11 & 233.307 & 15.136 \\
\hline 12 & 287.911 & 18.678 \\
\hline Total & 3.041 .257 & 197.302 \\
\hline Rata-rata & 253.438 & 16.442 \\
\hline
\end{tabular}

Kehilangan air komersial dapat juga disajikan dalam bentuk persentase untuk disiapkan dalam neraca air. Maka dapat diketahui dari besar volume kehilangan air sebesar $197.302 \mathrm{~m}^{3} /$ tahun dibagi dengan volume air yang terdistribusi dalam sistem sebesar $5.244 .141 \mathrm{~m}^{3} /$ tahun sehingga didapatkan persentase kehilangan air komersial pada neraca air yaitu $3.76 \%$ yang disajikan pada Tabel 9 .

Tabel 9.

Persentase Kehilangan Air Komersial dalam Neraca Air

\begin{tabular}{ccc}
\hline \hline Kehilangan Air & Volume Air \\
Komersial (m $\mathrm{m}^{3} /$ tahun $)$ & Distribusi (m $\mathrm{m}^{3} /$ tahun $)$ & $\%$ \\
\hline 197.302 & 5.244 .141 & $3,76 \%$ \\
\hline
\end{tabular}

- Kehilangan Air Fisik

Kehilangan air fisik meliputi kebocoran pada pipa, kebocoran pada limpahan reservoir, dan kebocoran pada pipa sambungan layanan hingga ke meter pelanggan. Untuk mendapatkan hasil dari seberapa besar kehilangan air fisik ini terjadi maka lebih mudah setelah mengetahui kehilangan air total dikurangi dengan kehilangan air komersial. Persentase kehilangan air fisik dapat dihitung dengan menggunakan rumus berikut.

Kehilangan Air Fisik $=$ Kehilangan Air - Kehilangan Air Komersial

$$
=100 \%-6,49 \%=93,51 \%
$$

Perhitungan besar kehilangan air fisik dari kehilangan air total secara rinci disajikan pada Tabel 10.

Tabel 10.

Kehilangan Air Fisik dari Kehilangan Air Total

\begin{tabular}{ccc}
\multicolumn{2}{c}{ Kehilangan Air Fisik dari Kehilangan Air Total } \\
\hline \hline Bulan ke- & $\begin{array}{c}\text { Kehilangan } \\
\text { Air } \\
\left(\mathrm{m}^{3}\right)\end{array}$ & $\begin{array}{c}\text { Besar Kehilangan } \\
\text { Air Fisik x 93,51\% } \\
\left(\mathrm{m}^{3}\right)\end{array}$ \\
\hline 1 & 278.272 & 260.219 \\
2 & 244.391 & 228.536 \\
3 & 273.644 & 255.891 \\
4 & 320.702 & 299.896 \\
5 & 240.845 & 225.220 \\
6 & 242.578 & 226.841 \\
7 & 282.319 & 264.004 \\
8 & 201.509 & 188.436 \\
9 & 237.013 & 221.637 \\
10 & 198.766 & 185.871 \\
11 & 233.307 & 218.171 \\
12 & 287.911 & 269.233 \\
Total & 3.041 .257 & 2.843 .955 \\
Rata-rata & 253.438 & 236.996 \\
\hline \hline
\end{tabular}

Kehilangan air fisik dapat juga disajikan dalam bentuk persentase untuk disiapkan dalam data neraca air maka dapat diketahui dari besar volume kehilangan air sebesar 93,51\% yaitu 2.843.955 $\mathrm{m}^{3} /$ tahun dibagi dengan volume air terdistribusi dalam sistem sebesar $5.244 .141 \mathrm{~m}^{3} /$ tahun sehingga didapatkan persentase kehilangan air fisik pada neraca air yaitu 54,23\% yang disajikan pada Tabel 11 .

Tabel 11.

Persentase Kehilangan Air Fisik dalam Neraca Air Kehilangan Air Volume Air

Fisik Distribusi

$(\%)$

\begin{tabular}{ccc}
$\left(\mathrm{m}^{3} /\right.$ tahun $)$ & $\left(\mathrm{m}^{3} /\right.$ tahun $)$ & \\
\hline 2.843 .955 & 5.244 .141 & $54,23 \%$ \\
\hline
\end{tabular}

- Air yang Tidak Bisa Direkeningkan (NRW)

Air yang tidak bisa direkeningkan atau biasa disebut non revenue water (NRW) ialah jumlah dari kehilangan air dan konsumsi air resmi yang tidak bisa direkeningkan dapat dijelaskan dalam rumus berikut.

NRW = Kehilangan air + Konsumsi resmi tidak berekening

Perhitungan NRW PDAM Kota Kendari Cabang Pohara dihitung berdasarkan komponen penyusun masing-masing 
yaitu kehilangan air dan konsumsi resmi tidak berekening. Hasil perhitungan NRW secara lebih rinci disajikan pada Tabel 12.

Tabel 12.

Hasil Perhitungan NRW PDAM Kota Kendari Cabang Pohara Tahun 2015

\begin{tabular}{cccc}
\hline \hline $\begin{array}{c}\text { Konsumsi Resmi } \\
\text { Tidak Berekening }\end{array}$ & $\mathrm{m}^{3} /$ tahun & $\begin{array}{c}\text { Kehilangan } \\
\text { Air }\end{array}$ & $\mathrm{m}^{3} /$ tahun \\
\hline Bermeter & 0 & Komersial & 197.302 \\
Tidak Bermeter & 0 & Fisik & 2.843 .955 \\
NRW $\left(\mathrm{m}^{3} /\right.$ tahun $)$ & & 3.041 .257 & \\
\hline \hline
\end{tabular}

- Komponen Kehilangan Air

Komponen kehilangan air PDAM Kota Kendari Cabang Pohara dapat diketahui dari perhitungan pada poin-poin sebelumnya, untuk mempermudah pemahaman disajikan Tabel 13.

Tabel 13.

Komponen Kehilangan Air PDAM Kota Kendari Cabang Pohara

\begin{tabular}{|c|c|c|c|}
\hline \multicolumn{2}{|c|}{ Komponen } & $\%$ & ( $\mathrm{m}^{3} /$ tahun $)$ \\
\hline $\begin{array}{c}\text { Kehilangan Air } \\
\text { Komersial }\end{array}$ & Akurasi meter air & $6,49 \%$ & 197.302 \\
\hline $\begin{array}{c}\text { Kehilangan Air } \\
\text { Fisik }\end{array}$ & $\begin{array}{l}\text { Kebocoran pipa } \\
\text { Kebocoran dan } \\
\text { berlebih air } \\
\text { di tangki } \\
\text { Kebocoran pada } \\
\text { sambungan } \\
\text { sampai meteran }\end{array}$ & $93,51 \%$ & 2.843 .955 \\
\hline
\end{tabular}

- Kerugian Finansial Akibat Kehilangan Air

Kehilangan air berupa satuan volume perlu dikonversikan pada satuan ekonomi yaitu rupiah, sehingga dapat diketahui seberapa besar kerugian finansial akibat kehilangan air sebagaimana disajikan pada Tabel 14.

Kehilangan air yang tidak bisa direkeningkan $(\mathrm{NRW})=$ Tarif rata-rata dalam tahun atau bulan $\left(\mathrm{Rp} / \mathrm{m}^{3}\right) \times \mathrm{NRW}\left(\mathrm{m}^{3} /\right.$ waktu)

Tabel 14.

Konversi Kehilangan Air

\begin{tabular}{|c|c|c|c|c|}
\hline NRW & $\begin{array}{r}\text { Konsum } \\
\text { Tidak B } \\
\end{array}$ & $\begin{array}{l}\text { i Resmi } \\
\text { ekening }\end{array}$ & \multicolumn{2}{|c|}{ Kehilangan Air } \\
\hline Harga & Bermeter & $\begin{array}{l}\text { Tidak } \\
\text { Bermeter }\end{array}$ & $\begin{array}{l}\text { Kehilangan } \\
\text { Air } \\
\text { Komersial }\end{array}$ & $\begin{array}{c}\text { Kehilangan } \\
\text { Air Fisik }\end{array}$ \\
\hline $\mathrm{Rp} / \mathrm{m}^{3}$ & & & $\mathrm{n}^{3} /$ tahun & \\
\hline \multirow{3}{*}{$\begin{array}{c}11.46 \\
4\end{array}$} & 0 & 0 & 197.302 & 2.843 .955 \\
\hline & \multicolumn{4}{|c|}{$\mathrm{Rp} /$ tahun } \\
\hline & 0 & 0 & $\begin{array}{c}2.261 .825 .70 \\
0 \\
\end{array}$ & $\begin{array}{c}32.602 .539 .61 \\
2 \\
\end{array}$ \\
\hline \multirow[b]{2}{*}{ NRW } & \multicolumn{3}{|c|}{$\mathrm{m}^{3} /$ tahun } & 3.041 .257 \\
\hline & \multicolumn{3}{|c|}{ Rp/tahun } & $\begin{array}{c}34.864 .365 .31 \\
1 \\
\end{array}$ \\
\hline
\end{tabular}

\section{- Neraca Air}

Metode yang digunakan untuk mengetahui aliran air ialah menggunakan metode water balance atau neraca air yang diidentifikasi selama 1 tahun disajikan pada Tabel 15.
Tabel 15.

Neraca Air PDAM Kota Kendari Cabang Pohara

\begin{tabular}{|c|c|c|c|c|c|c|}
\hline & Konsumsi & & \multicolumn{2}{|c|}{ Bermeter berekening } & \multicolumn{2}{|l|}{ Air yang bisa } \\
\hline & Resmi & & \multicolumn{2}{|l|}{$41,67 \%$} & \multicolumn{2}{|l|}{ direkeningkan } \\
\hline Volume Input & $42,01 \%$ & Konsumsi & \multicolumn{2}{|c|}{$2.185 .212 \mathrm{~m}^{3} / \mathrm{tahun}$} & & \\
\hline Sistem & & Resmi & Rp25.050.835.707 & /tahun & \multicolumn{2}{|l|}{$42,01 \%$} \\
\hline \multirow[t]{5}{*}{$100 \%$} & 2.202 .884 & Berekening & \multicolumn{2}{|c|}{ Tak bermeter berekening } & & \\
\hline & $\mathrm{m}^{3} / \mathrm{tahun}$ & & \multicolumn{2}{|l|}{$0,34 \%$} & \multicolumn{2}{|c|}{$2.202 .884 \mathrm{~m}^{3} /$ tahun } \\
\hline & Rp 25.253.424.000 & & \multicolumn{2}{|c|}{$17.672 \mathrm{~m}^{3} /$ tahun } & & \\
\hline & /tahun & & Rp202.588.293 & /tahun & Rp 25.253.424.000 & Itahun \\
\hline & & Konsumsi Resmi & \multicolumn{2}{|l|}{ Bermeter $(0)$} & \multicolumn{2}{|c|}{ Air yang tidak bisa } \\
\hline 5.244 .141 & & Tak Berekening & \multicolumn{2}{|c|}{ Tak Bermeter (0) } & \multicolumn{2}{|l|}{ direkeningkan } \\
\hline \multirow[t]{5}{*}{$\mathrm{m}^{3} / \mathrm{tahun}$} & & Kebocoran Komersial & \multirow{2}{*}{\multicolumn{2}{|c|}{ Sambungan Liar (0) }} & \multicolumn{2}{|l|}{ (NRW) } \\
\hline & Kehilangan & $3,76 \%$ & & & & \\
\hline & air & 197.302 & \multicolumn{2}{|c|}{ Pembacaan meter air } & & \\
\hline & & $\mathrm{m}^{3} /$ tahun & \multicolumn{2}{|l|}{$3,76 \%$} & \multicolumn{2}{|l|}{$57,99 \%$} \\
\hline & $57,99 \%$ & Rp2.261.825.700 & \multicolumn{2}{|c|}{$197.302 \mathrm{~m}^{3} /$ tahun } & & \\
\hline Rp 60.117.789.311 & & /tahun & Rp2.261.825.700 & /tahun & & \\
\hline \multirow[t]{6}{*}{ /tahun } & 3.041 .257 & Kebocoran Fisik & \multicolumn{2}{|c|}{ Kebocoran dan kelebihan } & 3.041 .257 & $\mathrm{~m}^{3} /$ tahun \\
\hline & $\mathrm{m}^{3} / \mathrm{tahun}$ & $54,23 \%$ & \multicolumn{2}{|l|}{ air di tangki } & & \\
\hline & & 2.843 .955 & \multicolumn{2}{|c|}{ Kebocoran pada pipa } & & \\
\hline & Rp 34.864.365.311 & $\mathrm{m}^{3} /$ tahun & \multicolumn{2}{|c|}{ Kebocoran pada } & Rp 34.864.365.311 & /tahun \\
\hline & /tahun & Rp32.602.539.612 & \multicolumn{2}{|c|}{ sambungan layanan } & & \\
\hline & & /tahun & \multicolumn{2}{|c|}{ sampai meteran } & & \\
\hline
\end{tabular}

- Pendapatan dari Penurunan Kehilangan Air Komersial

Program penurunan kehilangan air komersial yang direkomendasikan dilakukan dalam beberapa tahap dimulai dari tahun 2017 hingga tahun 2019 dengan persentase penurunan setiap tahunnya sebesar $1,25 \%$. Volume air yang diselamatkan dikalikan dengan harga tarif rata-rata air yang didapatkan pada perhitungan sebelumnya yaitu Rp 11.464,sehingga didapatkan jumlah air yang dapat direkeningkan dalam kurun waktu 3 tahun adalah $7.330 \mathrm{~m}^{3}$. Tambahan pendapatan yang dapat diperoleh PDAM Kota Kendari Cabang Pohara adalah sebesar Rp 84.034.450,-.

- Rekomendasi Strategi Penurunan Kehilangan Air Komersial

Temuan-temuan berikut ini ialah data penunjang yang digunakan sebagai pertimbangan dalam menentukan strategi penurunan kehilangan air komersial yaitu:

a. Pembacaan meter air

PDAM Kota Kendari telah melakukan pembacaan meter air dengan menggunakan alat komunikasi (HP) yang telah terinstall dengan software sehingga pembacaan dapat dilakukan dengan sistem barcode. Namun, tidak semua pembacaan meter air dilakukan menggunakan alat komunikasi tersebut.

b. Jenis meter air yang dipasang tidak sesuai

Adanya beberapa meter air yang seharusnya digunakan untuk kelompok industri, pelabuhan, niaga besar, dan sejenisnya digunakan oleh rumah tangga.

c. Umur dan kelas meter

Hasil survey didapatkan keterangan umur dan kelas meter air yang kemudian dikelompokkan mulai dari 1 tahun, 2 tahun, 3 tahun, 6 tahun, dan lebih dari 6 tahun serta kelas A, B, dan C. Keterangan umur dan kelas meter air yang telah dikelompokkan dapat dilihat pada Tabel 16.

d. Kontinuitas aliran

Menurut laporan PDAM Kota Kendari Cabang Pohara tahun 2015 jam operasional kinerja IPAM masih sangat rendah 
yaitu hanya $15 \mathrm{jam} / \mathrm{hari}$

\section{e. Tampering}

Temuan dugaan penyadapan air menggunakan pompa sebanyak 45 SR yang tersebar di beberapa titik pelayanan PDAM Kota Kendari Cabang Pohara.

- Strategi Penurunan Kehilangan Air Komersial

Tabel 16.

Pengelompokkan Meter Air Berdasarkan Umur dan Kelas Meter

\begin{tabular}{ccc}
\hline Umur & $\mathrm{B}$ & $\mathrm{C}$ \\
\hline 1 tahun & 14 & 4 \\
2 tahun & 3 & 3 \\
3 tahun & 4 & 26 \\
6 tahun & 10 & 0 \\
$>6$ tahun & 16 & 0 \\
\hline \hline
\end{tabular}

Penurunan kehilangan air pada PDAM Kota Kendari Cabang Pohara difokuskan pada penurunan kehilangan air komersial karena relatif lebih murah dan mudah dalam pelaksanaannya. Adapun strategi yang direkomendasikan untuk menangani kehilangan air komersial pada PDAM Kota Kendari Cabang Pohara ialah:

a. Penggantian meter air pelanggan baik meter air dengan penyimpangan positif maupun negatif. Meter air yang digunakan ialah meter air kelas B yang tidak berumur lebih dari 6 tahun dan meter air kelas $\mathrm{C}$ yang tidak berumur lebih dari 3 tahun. Meter air yang digunakan juga harus sesuai dengan kelompok pelanggan yang menggunakan berdasarkan SNI 2547:2008 tentang Spesifikasi Meter Air [5].

b. Dilakukan kalibrasi pada meter air pelanggan karena penyimpangan pembacaan meter air memberikan kontribusi terhadap kehilangan air PDAM dan kerugian pada pihak pelanggan. Kalibrasi dilakukan dengan menggunakan alat Portable Test Bench.

c. Penerapan sistem pembacaan meter air pelanggan menggunakan alat komunikasi (HP) secara menyeluruh.

d. Membentuk tim penertiban sambungan liar di berbagai titik kemudian melakukan penggalian agar menjadi barang bukti untuk tindakan selanjutnya berupa pendendaan atau pemberkasan ke kepolisian.

e. Pemasangan water meter pada jaringan transmisi dan distribusi.

f. Membuat pemetaan jaringan menggunakan GIS (Geographic Information Systems).

g. Membentuk tim pengendalian NRW yang bersifat tetap dan terstruktur yang bertugas.

h. Pencarian kebocoran secara aktif baik kebocoran fisik melalui step test dan kebocoran non fisik.

\section{KESIMPULAN/RINGKASAN}

Berdasarkan hasil penelitian dapat diambil kesimpulan sebagai berikut:
1. Komponen kehilangan air komersial PDAM Kota Kendari Cabang Pohara meliputi konsumsi tak resmi yaitu sambungan liar yang tidak ditemukan (0) dan komponen ketidakakuratan meter air sebanyak 43 sampel dari total 80 sampel yang diuji. Sedangkan tingkat kehilangan air komersial yang terjadi pada PDAM Kota Kendari Cabang Pohara sebesar 3,76\% dari 57,99\% total tingkat kehilangan air.

2. Perhitungan neraca air (water balance) PDAM Kota Kendari Cabang Pohara adalah sebagai berikut:

a. Volume input air sebesar 5.244.141 $\mathrm{m}^{3} /$ tahun yang terbagi menjadi konsumsi resmi ditambah volume kehilangan air

b. Volume output air sebesar $5.244 .141 \mathrm{~m}^{3} /$ tahun yang terbagi menjadi air yang bisa direkeningkan dan air yang tidak bisa direkeningkan

- Konsumsi resmi ialah volume air yang bisa direkeningkan sebesar $2.202 .884 \mathrm{~m}^{3} /$ tahun

- Kehilangan air ialah volume air yang tidak bisa direkeningkan sebesar $3.041 .257 \mathrm{~m}^{3} /$ tahun yang terbagi menjadi kehilangan air fisik sebesar 2.843.955 $\mathrm{m}^{3} /$ tahun dan kehilangan air komersial sebesar 197.302 $\mathrm{m}^{3} /$ tahun .

3. Kerugian finansial yang diakibatkan oleh kehilangan air komersial PDAM Kota Kendari Cabang Pohara pada tahun 2015 adalah sebesar Rp 2.261.825.700,-

4. Strategi pengendalian tingkat kehilangan air komersial yang disarankan untuk dilakukan adalah penggantian meter air yang tepat dan sesuai dengan kelompok pelanggan yang menggunakan, dilakukan kalibrasi pada meter air pelanggan secara berkala, penerapan sistem pembacaan meter air pelanggan menggunakan alat komunikasi (HP) secara menyeluruh, membentuk tim penertiban sambungan liar, memantau pelayanan air yang tidak teratur, pemasangan water meter pada jaringan transmisi dan distribusi, membuat pemetaan jaringan menggunakan GIS, membentuk tim pengendalian NRW, dan pencarian kebocoran.

\section{DAFTAR PUSTAKA}

[1] B. Syahputra, "Penyusunan Neraca Air sebagai Fungsi Kontrol Laju Kehilangan Air PDAM (Studi Kasus PDAM Kota Semarang)," 2011.

[2] International Water Association (IWA), Losses for Water Systems : Standard Terminology and Recommended Performance Measures Water Balance. IWA Publishing, 2001.

[3] N. A. Siregar and A. P. Mulia, "Evaluasi Kehilangan Air (Water Losses) PDAM Tirtanadi Padangsidimpuan di Kecamatan Padangsidimpuan Selatan," J. Univ. Sumatera Utara, vol. 3, no. 1, 2013.

[4] M. Farley, A Guide to Understanding Water Losses. 2008.

[5] Badan Standarisasi Nasional Indonesia (BSNI), "SNI 2547: 2008 Spesifikasi Meter Air,” Jakarta, 2008. 